\title{
Reinforcing the occurrence or nonoccurrence of interim drinking
}

\author{
DOUGLAS REBERG \\ University of Western Ontario, London, Ontario N6A 5C2, Canada
}

\begin{abstract}
Four pairs of rats were studied in a yoked control design intended to determine if an interim activity (schedule-induced drinking) was sensitive to operant contingencies. Food was always presented on a fixed-time 30 -sec schedule. Additionally, a positive or negative operant contingency was in effect during the first $6 \mathrm{sec}$ of each interval. The positive (drink/food) contingency produced an extra food presentation at the 6th second of an interval if the lead rat drank at least once in the first $6 \mathrm{sec}$. The negative (no-drink/food) contingency produced an extra food presentation only if the lead rat did not drink in the first 6 sec. Two pairs of rats were first exposed to the positive contingency and then to the negative contingency. Two pairs received training in the reverse order. In drink/food training, all lead rats developed patterns of drinking that produced extra food presentations in most intervals. There were some indications that the positive contingency facilitated early acquisition of drinking, but the yoked rats eventually developed temporal distributions and asymptotic levels of drinking comparable to those that occurred in lead rats. In no-drink/food training, the two lead rats initially exposed to the positive contingency showed high levels of drinking inappropriate to the negative contingency, but the two lead rats initially exposed to the negative contingency showed appropriately low levels of drinking. The latter effects seem attributable to the no-drink/food contingency.
\end{abstract}

It is well known that periodic schedules of food delivery produce at least two activities that occur at different times in the interreinforcement interval (Falk, 1977; Staddon \& Simmelhag, 1971). Late in the interval, animals usually stand near the site of food deliveries and perform food-related activities. Rats, for example, contact the food cup (Staddon \& Ayres, 1975; see also Reberg, Mann, \& Innis, 1977), and pigeons peck with a distinctive foodrelated topography (Reberg, Innis, Mann, \& Eizenga, 1978). Different activities occur in the early seconds of the interval, when animals usually move from the food site and perform activities unrelated to food. Rats, for example, display polydipsic drinking at such times (Staddon \& Ayres, 1975), and pigeons perform such activities as circling (Staddon \& Simmelhag, 1971). Staddon (1977; Staddon \& Simmelhag, 1971) called attention to the differences between activities that occur early and late in interfood intervals by calling them "interim" and "terminal" activities. Those terms will also be used in this paper.

When Staddon and Simmelhag (1971) introduced

Research and manuscript preparation supported by a grant from the National Research Council of Canada to D. Reberg. Thanks are due to $\mathrm{S}$. Meltzer for assistance with data collection and analyses, and to N. K. Innis, B. Mann, and G. Moran for comments on an earlier version of this paper. Reprints are available from the author at the Department of Psychology, University of Western Ontario, London, Ontario N6A $5 \mathrm{C2}$, Canada. the concept of interim behavior, they specified that those activities are not directly affected by operant reinforcement. There are at least two reasons for that view (see, also, review by Staddon, 1977): (1) interim activities usually occur early in the interreinforcement interval, so that they rarely coincide with food, and are followed by other activities that do coincide with food. Interim activities thus seem rather well insulated from possible effects of operant reinforcement. (2) Some researchers (e.g., Falk, 1969; Flory \& Lickfett, 1974; Segal \& Oden, 1969) have shown that interim activities persist in spite of operant contingencies that might be expected to disrupt their occurrence. Segal and Oden (1969), for example, studied a procedure in which rats were given food on a fixed-time (FT) 60 -sec schedule. When the rat licked a drinking tube, food delivery was postponed for 30 or $60 \mathrm{sec}$ (depending on the condition). Polydipsia developed quickly in every rat despite the fact that it delayed food presentation.

But not all experiments have failed to show an effect of delay contingencies on interim behavior. Moran and Rudolph (in press), for instance, found that delay contingencies severely disrupted the development of polydipsia. They compared the performance of rats exposed to delay contingencies ranging from $10 \mathrm{sec}$ to $4 \mathrm{~min}$ with that of yoked control rats that received the same distribution of food deliveries independent of their drinking. The great majority of yoked rats displayed much higher levels of drinking than lead rats, suggesting that the delay 
contingency did interfere with the development of interim drinking. Moran and Rudolph also called attention to the fact that, in Segal and Oden's (1969) experiment, lead rats were usually slower to develop polydipsia than yoked controls. There are indications, then, that interim drinking may be influenced by at least some operant contingencies.

The present experiment was intended to provide further information about the extent to which operant contingencies affect an interim behavior (schedule-induced drinking). It is interesting that previous experiments on this problem have all focused on the effects of delay contingencies that reinforce nonoccurrence of interim drinking. Comparatively little is known about effects of positive contingencies that reinforce the occurrence of an interim behavior. Therefore, the effects of both types of operant contingency were studied in the present experiment.

\section{METHOD}

\section{Subjects}

The subjects were eight hooded rats obtained from the Quebec Breeding Farms. The rats were reduced to $80 \%$ of their freefeeding weights (shown in Table 1) by food deprivation, and maintained near those weights for the duration of the experiment. The rats were individually housed, with unrestricted access to water.

\section{Apparatus}

The apparatus was a response chamber (inside dimensions: $23 \times$ $20.5 \times 19 \mathrm{~cm}$ ). The end panels of the box were aluminum, and the side walls and top were Plexiglas. The floor was 18 evenly spaced stainless steel bars. Centered on the right-hand panel of the chamber was an inactive response lever. To the left of the lever was a recessed food cup (also inactive). Positioned to the right of the lever was the external housing of a dipper (Tech Serv Model 114-02) that protruded about $1.5 \mathrm{~cm}$ into the chamber. The dipper was used to present about $.05 \mathrm{~g}$ of hulled millet seed. Previous research in this laboratory (e.g., Reberg, Mann, \& Innis, 1977) has demonstrated that liquid dippers are suitable for presenting such granular reinforcers. The dipper was used in this experiment to prevent rats from "saving" food pellets for later consumption in a way that might affect the temporal parameters of the schedule (Staddon, 1977, p. 135).

Centered on the front wall of the response chamber was a drink tube that protruded about $1.5 \mathrm{~cm}$ into the chamber, attached to a graduated cylinder that permitted measurement of the quantity of water consumed in a session. The response chamber was situated on a table under a single light that illuminated the chamber but left the rest of the room in comparative darkness. Masking white noise was continually present in the experimental room. Solid-state programming and recording equipment was located in an adjacent room.

\section{Procedure}

The rats were first trained to eat millet from the dipper. Initially the dipper was raised for several seconds until the rat ate. Then the presentation time was rapidly decreased until the rat reliably emptied the dipper within $2 \mathrm{sec}$. All subsequent dipper presentations lasted 2 sec. Except for food presentation, the dipper was fully retracted and inaccessible.

The eight rats were then randomly assigned to four lead-yoke pairs. As shown in Table 1 , Rats 1 and $1 Y$ received three phases of training in an ABA sequence, Rats 2 and $2 Y$ received four phases in an $A B A B$ sequence, Rats 3 and $3 Y$ received four phases in a BABA sequence, and Rats 4 and $4 Y$ received three phases in a $\mathrm{BAB}$ sequence. $\mathrm{A}$ and $\mathrm{B}$ represent the procedures that will be called "drink/food" and "no-drink/food," respectively.

The drink/food and no-drink/food procedures were both based on a response-independent fixed-time (FT) 30 -sec schedule. Those response-independent food presentations will be called $30-\mathrm{sec}$ reinforcers. The drink/food and no-drink/food contingencies occurred in the first $6 \mathrm{sec}$ of the FT $30-\mathrm{sec}$ interval. In the drink/food procedure, rats could receive an extra food presentation at the 6th second of a 30 -sec interval if drinking occurred at least once in the first $6 \mathrm{sec}$ of that interval. Those drinkcontingent reinforcers will be called $6-\mathrm{sec}$ reinforcers. The no-drink/food procedure was similar except that 6-sec reinforcers occurred only if the rat did not drink in the first $6 \mathrm{sec}$. Each session lasted about $16 \mathrm{~min}$ and consisted of 31 FT $30-\mathrm{sec}$ reinforcers (defining 30 intervals per session) and a possible 30 6-sec reinforcers that could be earned by lead rats according to the drink/food or no-drink/food contingencies. The yoked rats received the same distribution of 30-sec and 6-sec reinforcers as their lead rats, but with no response-reinforcer contingency. The lead and yoked rats were run consecutively. Reinforcers for the yoked rats were programmed with a hand switch activated by the observer according to a written schedule determined by the lead rats.

Observation and recording of behavior. In all sessions, the rats' activities were recorded by one of two observers, who sat in a darkened area of the experimental room. A timing light (not observable by the rats) flashed briefly every $2 \mathrm{sec}$, at which time the observer noted activities that occurred in the preceding $2 \mathrm{sec}$. The activities recorded will be described in the Results section.

Contact relay circuits illuminated dim lights (also not observable by the rats) which indicated when the food dipper housing or

Table 1

Subjects, Weights (in Grams), and Order of Treatment

\begin{tabular}{|c|c|c|c|c|c|c|c|c|c|}
\hline \multirow[b]{2}{*}{ Rat } & \multirow{2}{*}{$\begin{array}{c}100 \% \\
\text { Weight }\end{array}$} & \multicolumn{2}{|c|}{ Phase 1} & \multicolumn{2}{|c|}{ Phase 2} & \multicolumn{2}{|c|}{ Phase 3} & \multicolumn{2}{|c|}{ Phase 4} \\
\hline & & Order & Sessions & Order & Sessions & Order & Sessions & Order & Sessions \\
\hline $\begin{array}{l}1 \\
1 Y\end{array}$ & $\begin{array}{l}371 \\
361\end{array}$ & D-F & 21 & ND-F & 13 & D-F & 31 & & \\
\hline $\begin{array}{l}2 \\
2 \mathrm{Y}\end{array}$ & $\begin{array}{l}447 \\
426\end{array}$ & D-F & 21 & ND-F & 19 & D-F & 26 & ND-F & 17 \\
\hline $\begin{array}{l}3 \\
3 Y\end{array}$ & $\begin{array}{l}416 \\
394\end{array}$ & ND-F & 22 & D-F & 51 & ND-F & 40 & D-F & 15 \\
\hline $\begin{array}{l}4 \\
4 Y \\
\end{array}$ & $\begin{array}{l}372 \\
353\end{array}$ & ND-F & 21 & D-F & 69 & ND-F & 29 & & \\
\hline
\end{tabular}

Note $-D \cdot F=$ drink $/$ food $; N D-F=$ no drink $/$ food . 
the water tube was touched. Contacts with the water tube were also registered by programming equipment which automatically scheduled extra food presentations according to the drink/food and no-drink/food contingencies. The observer held a pushbutton which, when pressed, cancelled a previous signal that the water tube had been touched. The cancellation switch was used whenever the rat touched the tube with his nose, paws, or tail, but did not actually lick.

The experimental room also contained a television camera. Certain sessions were videotaped for more extensive analysis and confirmation of activity patterns noted by the observer during the actual sessions.

\section{RESULTS}

The results will be presented in two parts. The first part will describe effects of the contingencies on drinking in the first $6 \mathrm{sec}$ of interreinforcement intervals. The second part will give a more complete description of selected rats' activities throughout the interreinforcement intervals.

\section{Effects of Drink/Food and No-Drink/Food Contingencies on Drinking}

The effects of the contingencies varied according to whether rats began with drink/food or no-drink/ food training. Data for each of those training sequences will be presented separately.

Rats beginning with drink/food training. Figure 1 shows the results for Rats $1,1 Y, 2$, and $2 Y$. The smaller graphs show total water intake for each session. The larger graphs show the number of 6-sec reinforcers earned by the lead rat in each session (heavy line, right vertical axis) and the frequency of drinking in the first $6 \mathrm{sec}$ of intervals (left vertical axis). Frequency of drinking is shown in terms of the number of 2-sec observation periods in which drinking was recorded. Since there were 30 FT 30-sec intervals per session, each of which contained three 2-sec observation periods in the first $6 \mathrm{sec}$, the maximum drinking score for any session is 90 .

The drink/food contingency was studied in Phase 1. Both lead rats began to drink early in training, so 6-sec reinforcers occurred in most intervals. The yoked rats also drank in Phase 1 , but lead rats generally drank earlier in training and more frequently than yoked controls. That effect was particularly evident in Rats 2 and $2 Y$.

When the contingency was changed to no-drink/ food in Phase 2, both lead rats showed a noticeable increase of drinking in the first $6 \mathrm{sec}$. Consequently, the number of 6-sec reinforcers dropped sharply. Rat 1Y also drank more often in Phase 2, but Rat $2 Y$ showed no appreciable increase from Phase 1 levels.

Reintroducing the drink/food contingency in Phase 3 produced several effects. At first, Lead Rats 1 and 2 (as well as Yoked Rat 1Y) drank throughout the first $6 \mathrm{sec}$ of nearly every interval,
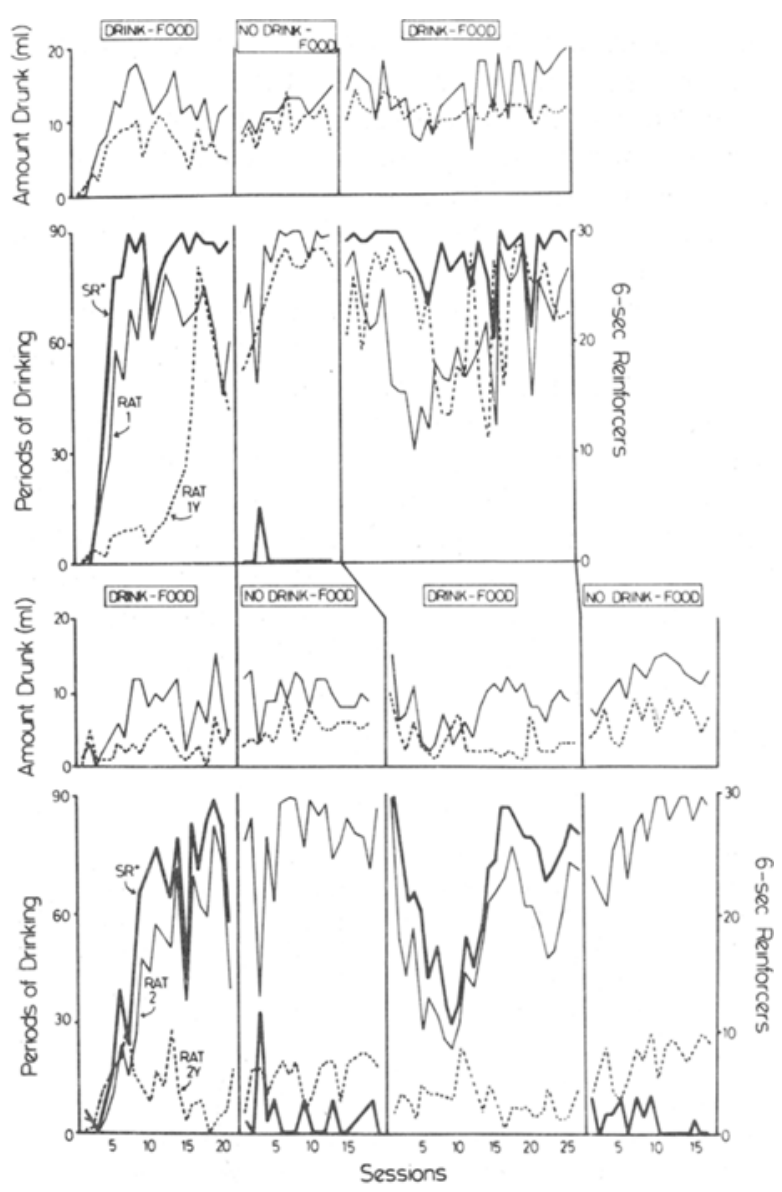

Figure 1. Periods of drinking, number of 6-sec reinforcers earned, and amount drunk for Rats $1,1 Y, 2$, and $2 Y$. See text for further details.

which immediately increased the number of 6-sec reinforcers obtained. Later, several sessions occurred in which drinking decreased sharply, followed by recovery to levels generally below those observed in Phase 2. That pattern occurred in Rats 1, 1Y, and 2. Rat $2 Y$ generally drank less often in Phase 3 than in Phase 2.

Rats 2 and $2 Y$ received an additional 17 sessions of exposure to the no-drink/food contingency in a fourth phase of training, which produced effects very similar to those in Phase 2 . Rat 2 showed an increase of drinking that resulted in a virtual elimination of 6-sec reinforcers. Drinking for Rat $2 \mathrm{Y}$ also increased noticeably.

Note that the total quantity of water consumed per session often remained quite stable despite changes in the frequency of drinking in the first 6 sec. In Phase 2, for instance, Rat 1 drank more often in the first $6 \mathrm{sec}$ but the total intake was about the same as in Phase 1. The reason for that stability was that increased drinking early in the interval was accompanied by decreased drinking later in the interval. In other cases, decreased drinking in the first $6 \mathrm{sec}$ was associated with similar decreases later 
in the interval and substantial decreases in total water intake (see, for example, Rat 2, Phase 3). Details of drinking patterns throughout the interval will be presented below.

Rats beginning with no-drink/food training. Figure 2 shows the results for Rats 3, 3Y, 4, and 4Y. When the no-drink/food contingency was in effect in Phase 1, Lead Rats 3 and 4 drank very infrequently so that 6-sec reinforcers occurred in practically every interval. Rat $3 \mathrm{Y}$ also failed to drink in Phase 1, but Rat $4 \mathrm{Y}$ began drinking early in Phase 1 and drank more frequently as training continued.

Several effects occurred in Phase 2 when the contingency was changed to drink/food. Lead Rats 3 and 4 did not drink at first, so few 6-sec reinforcers occurred in the early sessions of Phase 2 . By the fifth session of Phase 2, however, both lead rats began to drink so 6-sec reinforcers eventually occurred in most intervals. Later in Phase 2, Lead Rats 3 and
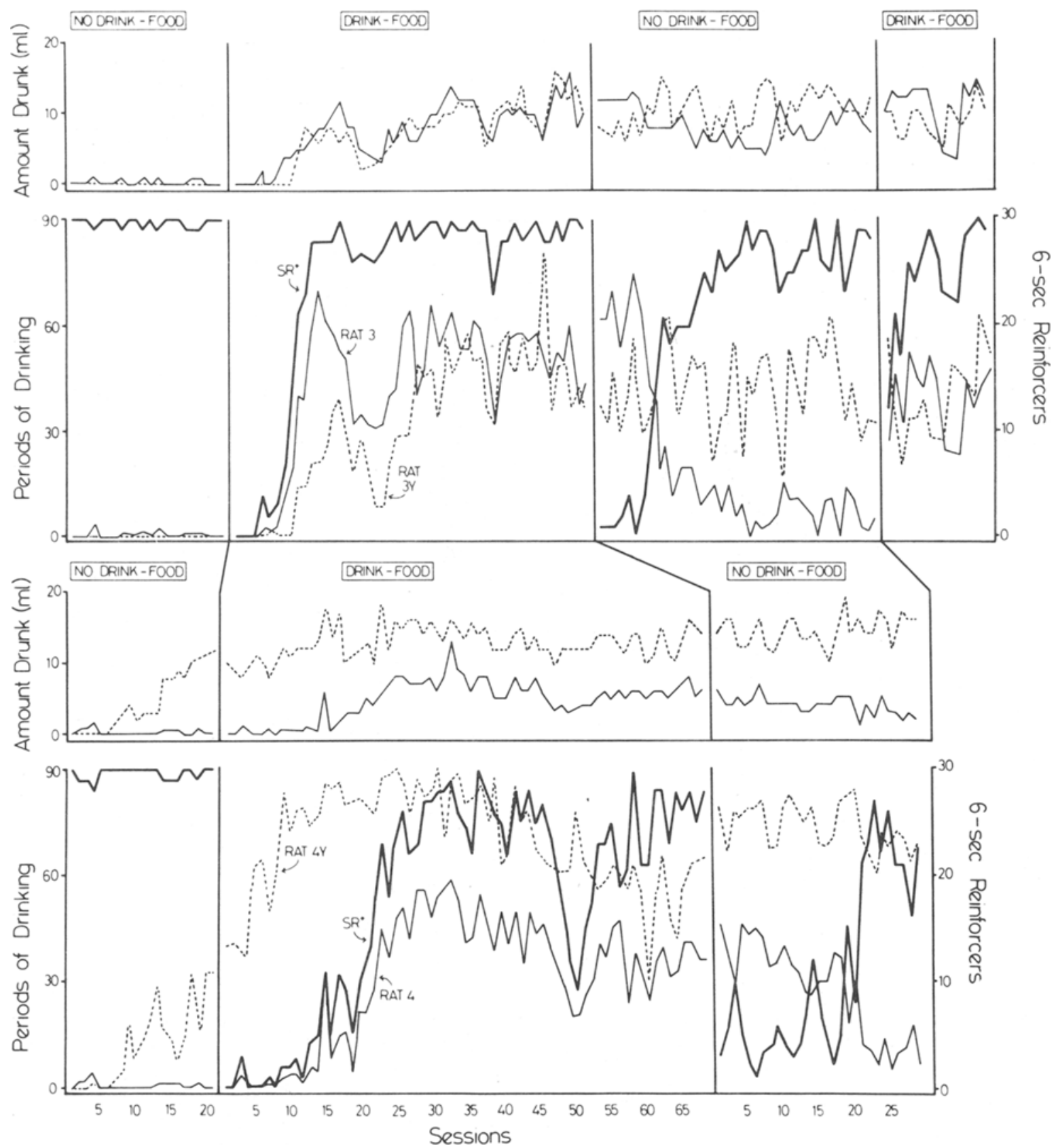

Figure 2. Periods of drinking, number of 6-sec reinforcers earned, and amount drunk for Rats $3,3 Y, 4$, and $4 Y$. See text for further details. 
4, as well as Yoked Rat 3Y, showed a decreaseand-recovery effect very similar to that observed during drink/food training in Rats $1,1 \mathrm{Y}$, and 2 . Rat 4Y showed a gradual and persistent decrease in drinking in the later sessions of Phase 2.

When the no-drink/food contingency was reintroduced in Phase 3, Lead Rats 3 and 4 initially drank in most intervals so that very few 6 -sec reinforcers were delivered. Subsequently, Rats 3 and 4 drank less often and gradually earned 6-sec reinforcers in most intervals. Drinking for Rat $3 \mathbf{Y}$ did not change in Phase 3, but Rat 4Y drank more often than in the later stages of Phase 2.

Rats 3 and $3 \mathrm{Y}$ received an additional exposure of 12 sessions to the drink/food contingency in Phase 4. Rat 3 drank in the first sessions of Phase 4 and in subsequent sessions, so comparatively few 6-sec reinforcers were lost as a result of the contingency change. Rat $3 Y^{\prime}$ 's drinking did not change appreciably from Phase 3.

Total water intake for Rats $3 Y$ and $4 Y$ remained quite stable over the phases of the experiment despite variations in the frequency of drinking in the first $6 \mathrm{sec}$. For Rats 3 and 4, total water intake tended to be lower in no-drink/food sessions (compare, for example, Phases 2 and 3 for Rats 3 and 4) because attenuation of drinking in the first $6 \mathrm{sec}$ of the interval during no-drink/food training was often associated with a similar attenuation later in the interval. Details of drinking activity throughout the interval will be presented in the following section.

\section{Temporal Distributions of Interim and Terminal Behavior}

This section will focus on the data for two pairs of rats: 1 and $1 Y$ (Figure 3) and 4 and $4 Y$ (Figure 4). The dependent variable for those figures is the percent of 2-sec observation periods in which certain activities occurred. Percentages were calculated by counting the number of times an activity occurred in an observation period and dividing by 30 (the number of times that observation period occurred per session). Rats often performed more than one activity in an observation period, or engaged in other activities not shown in the graph, so percentages do not always sum to 100 .

Rats 1 and 1Y. Figure 3 shows activities for Rats 1 and $1 Y$. The activities shown are drinking (D), food area (FA, defined as the rat's nose being in a $12 \times 10 \mathrm{~cm}$ floor area which defined the region of the chamber containing the dipper), and feeder contact (FC, defined as contact with the dipper housing sufficient to trigger the contact relay). Other activities were recorded (e.g., moving to the back of the chamber, grooming, grid-biting, and rearing), but they are not shown in Figure 3 so that the dominant behavior might be emphasized.
The first pair of graphs in Figure 3 shows activities for Rats 1 and $1 Y$ that occurred in the final session of drink/food training in Phase 1. Both rats performed two bouts of drinking in a typical $30-\mathrm{sec}$ interval, the first immediately after the $30-\mathrm{sec}$ reinforcer that began the interval and the second immediately after the 6-sec reinforcer. The rats usually moved to the feeder area and contacted the food dipper when not drinking.

In Phase 2, when the contingency was changed to no-drink/food, 6-sec reinforcers were practically eliminated for both rats because Rat 1 drank at least once in the first $6 \mathrm{sec}$ of most intervals. Interestingly, in the first session of Phase 2, both rats sometimes drank early in the interval, moved to the feeder area, then, after the 6-sec reinforcer did not appear, returned to the water bottle later in the interval. That pattern disappeared quickly in both rats, but it lasted somewhat longer for Rat 1 , which accounts for the slightly two-peaked apearance of the drink curve for Rat 1 in the first session of Phase 2. By the final session of Phase 2, Rats 1 and $1 Y$ both drank in a single bout, and usually moved to the food area when not drinking.

The final three pairs of graphs in Figure 3 show the activity patterns in Phase 3, when the drink/food contingency was reintroduced. Early in the first session of Phase 3, both rats often drank throughout the first $6 \mathrm{sec}$, stopped to eat the 6 -sec food presentation, then resumed drinking. By the end of the first session of Phase 3, however, drinking bouts in the first $6 \mathrm{sec}$ became noticeably shorter as the rats began to move to the dipper a few seconds before the food presentation was due. There was a further attenuation of drinking early in the interval as training continued (particularly noticeable for Rat 1 in the 12th session of Phase 3), and a return to drinking later in Phase 3 (the decrease-and-recovery effect described earlier and shown in Figure 1). As before, Rats 1 and $1 Y$ moved to the food area and contacted the dipper when not drinking.

Rats 4 and 4 Y. Figure 4 shows the activities for Rats 4 and $4 \mathrm{Y}$. The activities shown are drinking (D), food area (FA), and feeder contact (FC), defined as for Figure 3. Figure 4 also shows backof-chamber activity (BOC), defined as the rat's nose being behind the midline of the chamber.

The first pair of graphs shows the final session of Phase 1. Rat 4 drank very infrequently in Phase 1, so 6-sec food presentations occurred in virtually every interval. After eating, Rat 4 often moved from the food area, rearing and sniffing the top and upper walls at the back of the chamber. Rat $4 \mathrm{Y}$, in contrast to Rat 4, drank frequently in Phase 1, often after both food presentations. Both rats usually moved to the food area and contacted the dipper shortly before food presentation. 

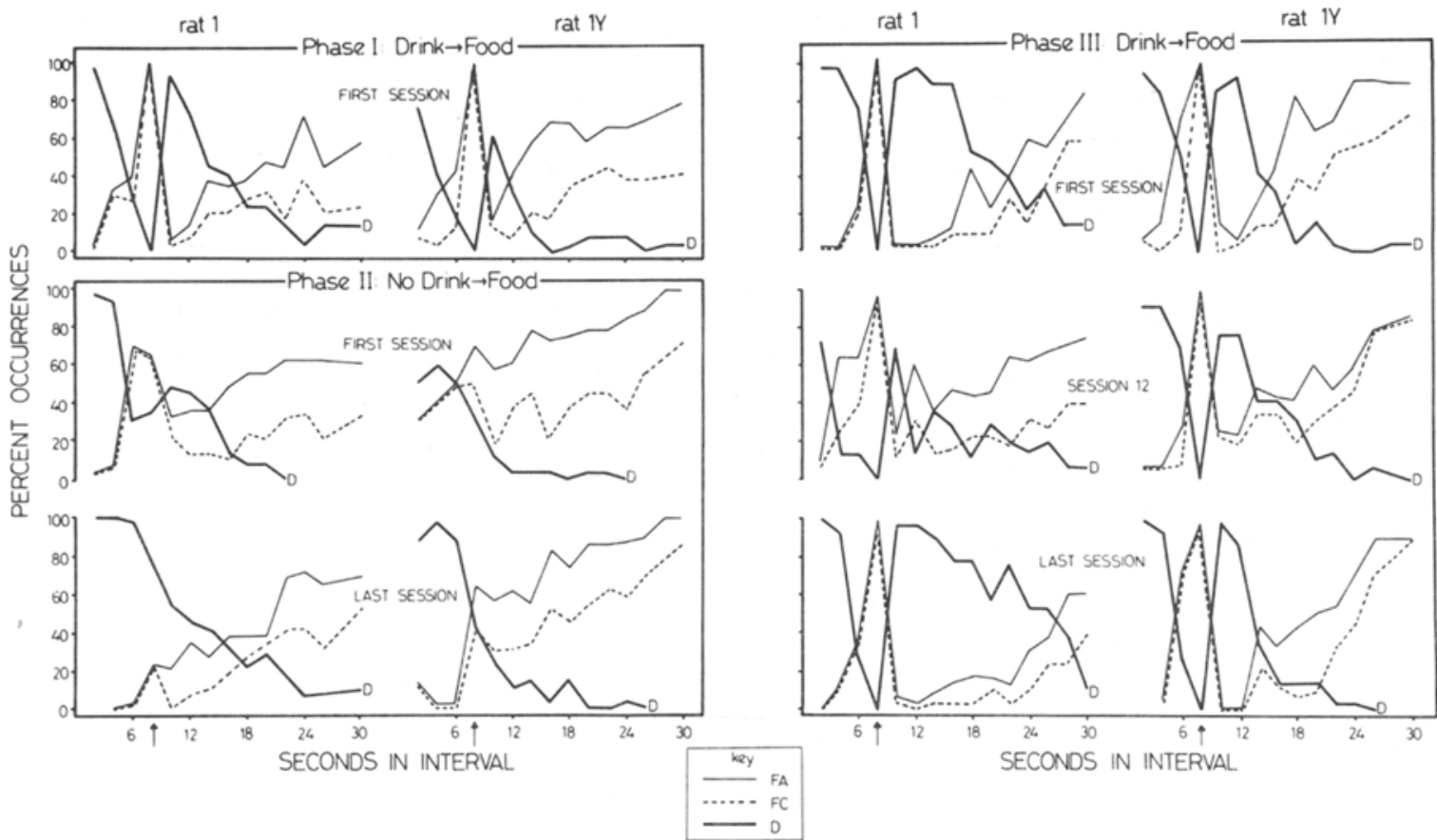

Figure 3. Percent occurrences of behavior patterns in 2 -sec observation periods of interreinforcement interval during sessions indicated for Rats 1 and 1 Y. D = drinking, FA = food area, FC = food-dipper contact. Food was sometimes presented between the 6th and 8th seconds of the interval (the fourth data point in the figures, indicated by an arrow). See text for further details.
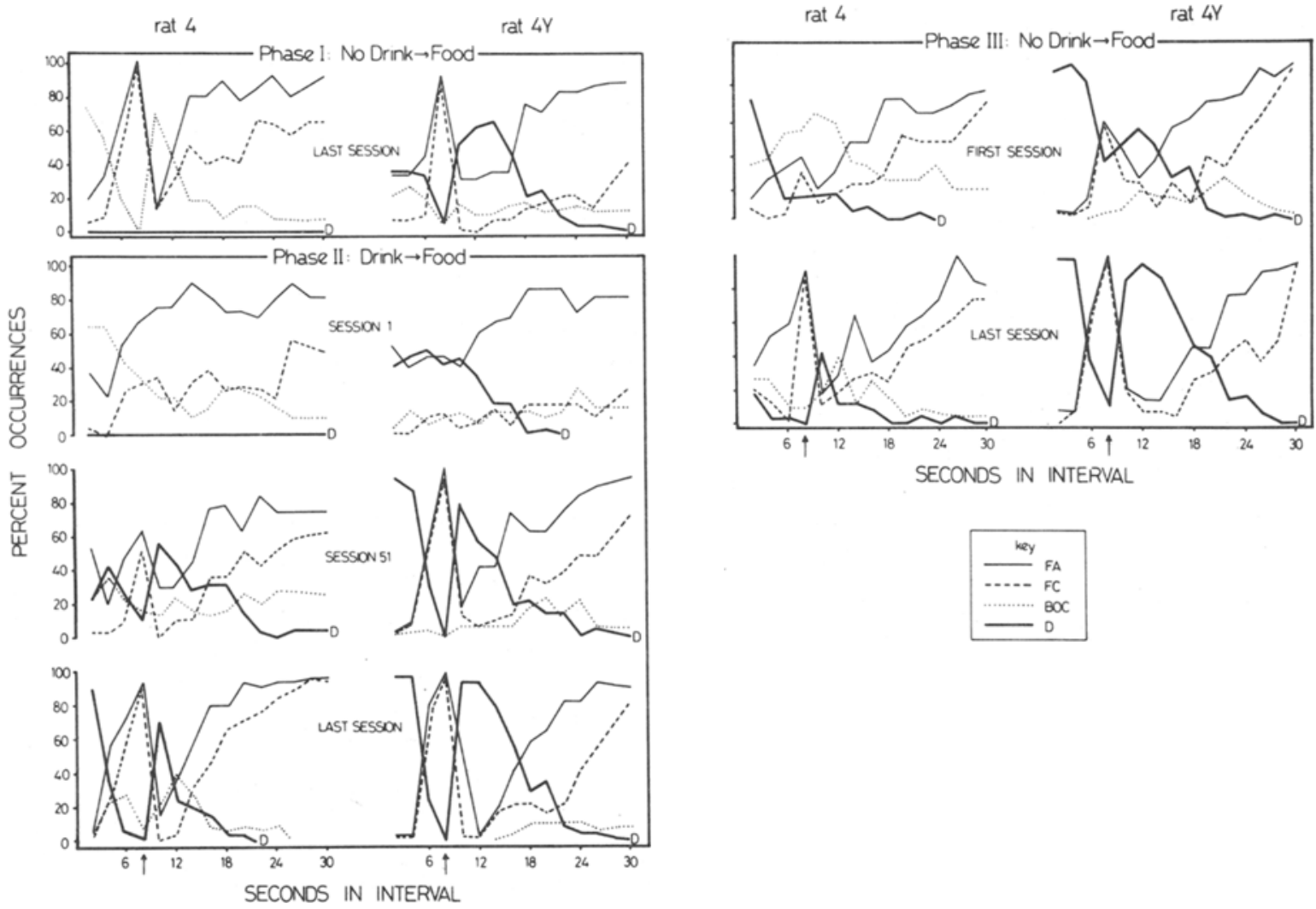

Figure 4. Percent occurrences of behavior patterns in 2-sec observation periods of interreinforcement interval during sessions indicated for Rats 4 and 4 Y. BOC = back of chamber. Other details as for Figure 3. 
In early sessions of drink/food training in Phase 2, Rat 4 did not drink, so 6-sec reinforcers were very infrequent. As training continued in Phase 2, drinking in the first $6 \mathrm{sec}$ of the interval and resulting food presentations became more frequent. By the end of Phase 2, Rat 4 drank after 6-sec and 30-sec food presentations. The increased drinking produced corresponding decreases in time spent at the back of the chamber. Rat 4Y's activities in Phase 2 included a single bout of drinking in the first sessions (where few 6-sec reinforcers occurred), but as 6-sec reinforcers became more frequent Rat $4 \mathrm{Y}$ resumed an activity pattern similar to that which occurred in Phase 1.

When the no-drink/food contingency was reintroduced in Phase 3, Rat 4 drank in most intervals so that 6 -sec reinforcers were largely eliminated. Later in training, Rat 4 decreased drinking to the point where 6-sec reinforcers occurred in most intervals. In place of drinking, Rat 4 occasionally resumed the pattern seen in Phase 1 of moving to the rear of the chamber and rearing. For Rat $4 Y$, drinking increased in the initial sessions of Phase 3, where few 6-sec reinforcers occurred. The slightly two-peaked curve for Rat $4 \mathrm{Y}$ in the first session of Phase 3 reflects the rat's occasional tendency to move to the food dipper early in the interval and then briefly resume drinking later in the interval after the 6-sec reinforcer did not appear. Like Rats 1 and $1 \mathrm{Y}$, described earlier, that pattern occurred very infrequently after the first session of Phase 3. As Phase 3 continued and 6-sec reinforcers became more common, Rat $4 \mathrm{Y}$ resumed a pattern of drinking after nearly every food presentation.

\section{DISCUSSION}

The effects of drink/food and no-drink/food contingencies will be summarized and discussed separately. Then a more general account of these data will be discussed.

\section{Effects of the Drink/Food Contingency}

In drink/food training, every lead rat developed drinking that produced 6-sec reinforcers in most intervals. For three lead rats $(1,2$, and 3$)$, acquisition of drinking under the drink/food condition was more rapid than for yoked controls. Rat 4 drank less often than Rat $4 \mathrm{Y}$ throughout drink/food training, but at least part of that deficit occurred because Rat $4 Y$ began drinking in Phase 1, before the introduction of the positive contingency for Rat 4 . It could reasonably be argued that the data from Lead Rats 1, 2, and 3 accurately represent the effects of drink/food training, and that the positive contingency facilitated development of interim drinking.
It is clear, however, that any facilitating effects of the positive contingency were confined to the early stages of training. With the exception of Rat $2 Y$, yoked animals equaled or exceeded the levels of drinking displayed by lead rats in drink/food sessions. Similar temporal patterns of drinking also occurred for lead and yoked rats. As other investigators have often reported (Staddon, 1977), drinking was usually a postfood, rather than a prefood, activity. When drinking did coincide with food delivery (as shown in Figure 3 in the Phase 3 data for Rats 1 and $1 \mathrm{Y}$ ), the response distributions shifted so that drinking mainly occurred in the first few seconds of the interval.

Of course, the positive contingency programmed food for drinking at any time in the first $6 \mathrm{sec}$ (an arrangement that might be described in the terminology of Staddon and Frank, 1975, as a "recycling" conjunctive FT 6-sec FR 1 contingency). Such contingencies have been known to produce unusual response distributions in which bouts of the reinforced response occur early in the interval (e.g., Staddon \& Frank, 1975). But Staddon and Frank also found similar response distributions in FT schedules, where there was no response requirement. Moreover, in the present experiment, lead rats showed similar tendencies to drink after food in the later portion of the interval (when there was not a drink/ food contingency) as well as in the first $6 \mathrm{sec}$ of the interval (when there was a drink/food contingency), and yoked rats also showed similar tendencies to drink after food both early and late in the interval. Thus, the operant contingency seems to have had very little, if any, effect on the temporal distribution of drinking.

In sum, the acquisition data from three of four pairs of rats provide some evidence that the positive contingency facilitated early development of interim drinking. There is little indication, however, that drink/food training had consistent effects on the asymptotic level or temporal patterning of drinking beyond those that would be expected in the absence of the contingency.

\section{Effects of the No-drink/Food Contingency}

The effects of no-drink/food training varied. Lead Rats 1 and 2 both responded to the introduction of the no-drink/food contingency in Phase 2 by drinking more often so that 6 -sec reinforcers were virtually eliminated. Those increases were shared to some extent by their yoked controls (much more clearly in Rat $1 Y$ than in Rat 2Y). Obviously, the no-drink/food contingency did not control drinking for Rats 1 and 2.

The no-drink/food contingency had very different effects for the other lead rats. In Phase 1, Rats 3 and 4 drank only occasionally, so that 6 -sec 
reinforcers occurred in most intervals. It is difficult to argue that the absence of drinking in Phase 1 was due to the no-drink/food contingency, however, because one of the yoked rats also failed to drink. In Phase 3, the data were less ambiguous. When the no-drink/food contingency was reintroduced in that phase, Rats 3 and 4 showed an appropriate decrease of drinking that did not occur in Rats $3 \mathrm{Y}$ or $4 \mathrm{Y}$. The differences between lead and yoked animals provide reasonably convincing evidence that the no-drink/food contingency did control the drinking of Rats 3 and 4, at least in Phase 3.

\section{Interpretation and Implications}

Most of the results of this experiment are consistent with the account of interim and terminal behavior proposed by Staddon (1977; Staddon \& Simmelhag, 1971). Although there are strong indications that Staddon's account does not apply to all reinforcers (Reberg, Innis, Mann, \& Eizenga, 1978; Reberg, Mann, \& Innis, 1977), it appears to be an accurate description of activities in periodic food schedules.

In brief, Staddon proposed that interim behavior occurs during $\mathrm{S}$ - periods of nonreinforcement (such as the early seconds of interreinforcement intervals when food has just occurred and is not due to occur again for some time). According to Staddon, interim activities are related to reinforcers other than the scheduled reinforcer. In periodic food schedules, for instance, animals often leave the site of food presentations and engage in interim activities such as drinking. Staddon also suggested that terminal behavior occurs during $\mathrm{S}+$ occasions (such as the later seconds of interreinforcement intervals, when food is imminent). Terminal activities, according to Staddon, are related to the scheduled reinforcer. In periodic food or water schedules, for example, pigeons often move to the site of reinforcement and peck with topographies similar to those that occur during eating or drinking (Reberg, Innis, Mann, \& Eizenga, 1978). Staddon also contended that Sand $S+$ produce interim and terminal motivational states that define the potential repertoire of interim and terminal activities.

Within that framework, the similarities between lead and yoked rats in drink/food training can be explained as follows: The data indicate that regular delivery of 6- and 30-sec reinforcers established a kind of "cyclic" schedule (Innis, in press) which alternated short and long interreinforcement intervals. For lead and yoked rats alike, short and long intervals were apparently divided into $S$ - (interim) and $\mathrm{S}+$ (terminal) components, a division that led most rats to display a bout of interim drinking after each food presentation. Such nonoperant drinking could have enabled the lead rats to "earn" 6-sec reinforcers independently of the drink/food contingency.

It should be emphasized that nonoperant interim and terminal processes may not provide a full explanation of all effects in drink/food training. In particular, the early development of drinking by three of four lead rats suggests that the positive contingency had at least some facilitating effects. But later in training, there were no consistent differences between lead and yoked rats. Perhaps the interim-terminal organization of interreinforcement intervals induces such high levels of drinking that there is little opportunity for the operant contingency to exert an effect beyond facilitating early development of drinking.

Staddon's account also provides an explanation of the no-drink/food results for Rats 1 and 2 and their yoked controls. For those rats, interim drinking had been previously established in Phase 1 . When the lead rats continued to drink in the early stages of no-drink/food training, 6-sec reinforcers were eliminated so that food presentations then occurred on a simple FT 30-sec schedule. The result was a new temporal discrimination in which the first $6 \mathrm{sec}$ of the interval became an interim period that generated drinking throughout. The infrequent occasions in which lead rats did not drink and 6-sec reinforcers occurred were apparently not enough to alter that interim status.

Rats 3 and 4 showed a very different effect. Evidentally, those rats were affected more by the no-drink/food contingency than by the interimterminal organization of interfood intervals. It is a distinct possibility that Rats 3 and 4 were more strongly affected by the negative contingency because they received no-drink/food training first, before drinking was well established. Moran and Rudolph (in press), who found severe disruption of drinking by a food-delay contingency, imposed the contingency from the beginning of training. Experiments that have introduced such contingencies after drinking has been well established have typically reported weaker disrupting effects and occasionally facilitating effects similar to those observed in Rats 1 and 2 (Flory \& Lick fett, 1974).

The main conclusion to draw from these results is that both procedures seem to involve interactions between the operant contingency and the rat's tendency to organize interreinforcement intervals (even comparatively brief intervals) into interim and terminal components. In the case of drink/food training, effects of the interim-terminal organization and the positive contingency are similar. In fact, data from yoked controls indicate that the interimterminal organization generates such a high level of drinking that the operant drink/food contingency may be overshadowed to the point where it exerts 
comparatively little control. In no-drink/food training, however, the negative contingency and the interim-terminal organization oppose each other. In this experiment, the interim-terminal organization apparently dominated in two rats ( 1 and 2$)$ and the negative contingency dominated in two ( 3 and 4 ). The reasons for the differences among rats are by no means certain, but it is an interesting possibility that early exposure promotes rats' detection of, and adaptation to, the operant contingency.

It should be emphasized that control of interim drinking by positive or negative contingencies should not be considered as support for the view that schedule-induced drinking is the result of an operant reinforcement mechanism. In fact, the present data indicate that drink/food training does not strongly influence asymptotic levels or temporal distributions of interim drinking, which, if anything, tends to support a nonreinforcement interpretation of interim behavior, such as Staddon's (1977). The major point, however, is that it may be incorrect to assert that interim activities in general (and drinking in particular) are not affected by reinforcement contingencies. The present results, like those of Moran and Rudolph (in press) show that interim drinking may be disrupted by a negative no-drink/food contingency, and they provide at least tentative evidence for facilitation by a positive drink/food contingency. The effects of other reinforcement contingencies on other interim activities clearly deserve further experimental attention.

One final point should be added about the interimterminal organization of interreinforcement intervals. It is surprising, in many respects, that a 6-sec interval terminating with food would be divided into $\mathrm{S}-$ and S + components. Despite previous reports of polydipsia in brief interreinforcement intervals (e.g., Flory, 1971), one might intuitively expect that a predictably brief interreinforcement interval (particularly one that occurs in the context of a much longer interval) would be an $\mathrm{S}+$ occasion which, according to Staddon's account, should promote terminal behavior throughout. Evidentally, even a 6-sec interfood interval contains a reinforcement probability gradient (Millenson, Allen, \& Pinker, 1977) sufficient to produce $S$ - (interim) and $\mathrm{S}+$ (terminal) components. There were, however, signs of instability of interim drinking in 6-sec intervals that frequently terminated with food (for example, the decrease-and-recovery effects observed in many yoked and master rats during periods of frequent 6-sec reinforcers). It would seem worthwhile for future experiments to provide detailed information about the minimum durations of intervals that are divided into interim and terminal components, as well as the properties of resulting interim and terminal activities.

\section{REFERENCES}

FALK, J. L. Conditions producing psychogenic polydipsia in animals. Annals of the New York Academy of Sciences, 1969, 157, 569-593.

FALK, J. L. The origin and functions of adjunctive behavior. Animal Learning \& Behavior, 1977, 5, 325-355.

Flory, R. K. The control of schedule-induced polydipsia: Frequency and magnitude of reinforcement. Learning and Motivation, 1971, 2, 215-227.

Flory, R. K., \& Lickfett, G. G. Effect of lick-contingent timeout on schedule-induced polydipsia. Journal of the Experimental Analysis of Behavior, 1974, 21, 45-55.

INNIS, N. K. Reinforcement as input: Temporal tracking on cyclic-interval schedules. In M. Commons \& J. A. Nevin (Eds.), Quantitative studies of operant behavior: Discriminative properties of reinforcement schedules. New York: Pergamon Press, in press.

Millenson, J. R., Allen, R. B., \& Pinker, S. Adjunctive drinking during variable and random-interval food reinforcement schedules. Animal Learning \& Behavior, 1977, 5, 285-290.

Moran, G., \& Rudolph, R. L. Operant processes in the development of schedule-induced polydipsia. Learning and Motivation, in press.

Reberg, D., Innis, N. K., Mann, B., \& Eizenga, C. "'Superstitious" behaviour resulting from periodic response-independent presentations of food or water. Animal Behaviour, 1978, 26, 506-519.

Reberg, D., Mann, B., '\& Innis, N. K. Superstitious behaviour for food and water in the rat. Physiology \& Behavior, 1977, 19, 803-806.

Segal, E. F., \& Oden, D. L. Schedule-induced polydipsia: Effects of providing an alternate reinforced response and of introducing a lick-contingent delay in food delivery. Psychonomic Science, 1969, 15, 153-154.

Staddon, J. E. R. Schedule-induced behavior. In W. K. Honig \& J. E. R. Staddon (Eds.), Handbook of operant behavior. Englewood Cliffs, N.J: Prentice-Hall, 1977.

Staddon, J. E. R., \& Ayres, S. L. Sequential and temporal properties of behavior induced by a schedule of periodic food delivery. Behaviour, 1975, 54, 26-49.

Staddon, J. E. R., \& Frank, J. A. The role of the peck-food contingency on fixed-interval schedules. Journal of the Experimental Analysis of Behavior, 1975, 23, 17-23.

Staddon, J. E. R., \& Simmelhag, V. L. The "superstition" experiment: A re-examination of its implications for the principles of adaptive behavior. Psychological Review, 1971, 78, 3-43.

(Received for publication March 13, 1979; revision accepted June 20, 1979.) 